\title{
AI ETHICS IN BUSINESS - A Bibliometric APPROACH
}

\author{
AlEXANDRU CONSTANTIN CIOBANU', GABRIELA MEȘNIȚĂ ${ }^{\mathrm{ii}}$
}

\begin{abstract}
Different businesses utilize Artificial intelligence (AI) to accelerate their digital transformation aiming to enhance specific outcomes while maximize productivity. Artificial Intelligence technologies have evolved rapidly and the interest to study this field has increased accordingly. In this context, the researchers were interested not only on the technical side of AI, but also on its impact on economy, or business. This study reviews, trough bibliometric techniques, the key players, and the main discussed topics, that contribute to the research of ethics of AI solutions implemented in business. We analyzed the most cited 2000 articles extracted from Scopus databases, and we used VOSviewer to visualize the identified data. The insights provided through this paper are valuable for the researchers that are exploring the AI ethics, as well as for specific audiences from different domains such as social sciences, business decision making, IT management, government, and public policy decision-makers.
\end{abstract}

Keywords: Artificial Intelligence, AI ethics, business, digital transformation, bibliometric analysis.

\section{INTRODUCTION}

Technology has always been a determining factor in the development process of societies or business organizations. Among the studies and research that were published on technology topics, there was always a particular interest related to the impact that the technology has on society. From a historical perspective, we can see that technology (generically speaking) faced an evolutive transformation, starting with the Industrial Revolution, Internet and computers

\footnotetext{
${ }^{i}$ Doctoral School of Economics and Business Administration, Alexandru Ioan Cuza University of Iaşi, Faculty of Economics and Business Administration, Iaşi, Romania, E-mail: alexandru. ciobanu@feaa.uaic.ro

ii Alexandru Ioan Cuza University of Iaşi, Faculty of Economics and Business Administration, Iaşi, Romania, E-mail: Gabriela.Mesnita@feaa.uaic.ro
} 
networking development, continuing with the rapid growth of what we call today as digitalization.

Today the technology is transforming our daily lives, impacting routine tasks such as how we are thinking, shopping, communicating, learning, working, and one pandora's box in this regard is the artificial intelligence (AI). There are lots of examples of AI applications that are used intensively either by individuals or by businesses, such as surveillance and automation systems, medical healthcare, farming, banking, smart homes, remote working, and many others. On the other side, the business is also trying to benefit as much as possible from the AI systems investing in this direction to optimize and automate daily routines.

Within this context, the AI is showing an unlimited potential, that is be beneficial for lots of organizations and individuals, especially from an economic viewpoint. There is market research (PwC, 2017:1) that is estimating that the greatest economic gains from AI will be in China (26\% boost to GDP in 2030) and North America ( $14.5 \%$ boost), equivalent to a total of $\$ 10.7$ trillion and accounting for aproximatively $70 \%$ of the global economic impact.

Note that due to the pandemic context, that began in 2019, we are witnessing a hyper-accelerated growth in the need for Artificial Intelligence systems in the business environment. McKinsey, in a recently published report (Mckinsey Global Institute, 2021:3), shows that throughout history companies have controlled costs and mitigated insecurity in two ways: by adopting automation solutions and redefining work processes to simplify the daily routine of employees. Thus, this report presents the situation from July 2020, where approximately $65 \%$ of the companies had on their agenda the automation of business processes through AI, and simultaneously in China the production of robots had exceeded the norms reached a year before the pandemic.

Alternatively, organizations are still exploring the opportunities offered by $\mathrm{AI}$ and at the same time self-educating about the possible risks associated with it. Another recent PwC study (Global CEO Survey, 2021:2) shows that 75\% of company leaders consider Artificial Intelligence useful to society, but a higher percentage, $84 \%$ of them believe that AI-based decisions need to be explained to be credible. For example, some of the top ethical issues on the research agenda today are related to unemployment and future of work, inequality and how wealth is created by machines and how these can affect human interactions. Other concerns are related to security, AI biases or privacy (Bossmann, 2016) and these are only some of them. 
In this context, the study of AI ethics becomes increasingly relevant because it is essential to explore the opportunities of AI as well as the potential risks. There is research that is promoting the idea of AI for people enumerating principles as part of an AI framework that overcomes associated risks (Floridi et. al., 2018:689707). It is obvious that there is a significant transformation of how different business environments become more productive and efficient due to digitization and through artificial intelligence solutions.

The main objective of this paper is to identify the current key players with interest in the research of the ethical concerns related to the AI ethics in business. To address it, we have integrated a bibliometric approach that will help explore the key topics and find the main contributors to the scientific literature. The scope of this scientific approach is to report on the potential opportunities for further research on the ethical debates surrounding the AI solutions implemented in business.

Therefore, this paper explores, what is the current landscape of the research articles that are addressing the topics of Artificial Intelligence ethics applied in business. Specifically, we will use bibliometric methods on data visualization to report on co-authorship and co-occurrence for the identified datasets, to retrieve what are the most cited articles, most influential institutions and journals, top countries researching this topic as well as the surfacing emerging topics. The datasets that will be chosen will be from Scopus, because it is the largest journal database that is currently available and it's offering also enriched capabilities to analyze the identified articles in results.

The next sections of the paper follow on the structure below: Section 2 focuses on the literature review of studies related to AI ethics in business; Section 3 will present the methodology used and the identified datasets used for the analyses; Section 4 will present the result of the bibliometric analyses and the key findings and finally Section 5 will offer the conclusions of this study as well as further research opportunities within the AI ethics field

\section{EXPLORING ETHICS AND AI}

To obtain the big picture on AI ethics in business, this paper will explore the related previous work done by other researchers interested on the AI ethics in business. In this section, we will review via a structured approach, 3 essential aspects of AI ethics: the current research related to the concepts of digital ethics in general (to understand the conceptual elements of ethics in technology), the AI impact on business (to explore how AI technologies is reshaping the business 
landscape), and the current main AI ethics debates. We will further introduce the bibliometric methods that were used within this study for data visualization, to report on the co-occurrences and co-authorship analysis.

\subsection{Analysis of the ethics concept from a digital perspective}

The importance of ethics research becomes important in the context of the development and implementation of AI solutions toward digitalized business environments. This importance is given by the multidisciplinary complexity of AI and by its impact on society, economy, technology.

Defining the term ethics can be difficult and this approach would also involve explaining related, interdependent concepts that can be associated with what could be explained to be ethical or not.

According to the Encyclopedia Britannica (Singer, 2021) the term ethics may refer to the discipline that deals with the study of the concepts of good or bad, right, or wrong from a moral perspective. The term can be associated with any theory of values and moral principles. Finally, the subject of ethics must be seen and interpreted in terms of particularities that may be related to religion, culture, profession and which are associated with a group of individuals, communities, organizations, etc.

For this paper, we will not rely on the philosophical descriptions for ethics but it's important to make some distinctions between metaethics, normative ethics, applied ethics (Marturano, 2002) or descriptive ethics (Nijsingh and Duwell, 2009). Issues that address the foundation of moral values, that explore morality as culturally relevant, or that link ethics to empirical principles can be seen as relating to metaethics. It explores the connection between values, motives for action and human motivation, and that must be seen from the perspective of moral responsibility (Sayre-McCord, 2014). Descriptive ethics describes and understand moral values, its judgments, and good practices, representing the foundation for normative ethics, the latter seeking to justify different ethical positions depending on certain principles or virtues (Stahl et al., 2016). Normative ethics is based on the ethics of virtue and the abovementioned Kantian ethics.

From all above perspectives, for this paper we consider relevant the concept of applied ethics which is based on proposing prescriptions in specific situations. Examples for applied ethics could be those represented by biomedical ethics, technology ethics, military ethics, environmental ethics, or computer ethics (Stahl et al., 2016). Considering the purpose of this paper, it is necessary to explore the 
evolution of computer ethics concept, which today is broadly called digital ethics. In large sense, the AI ethics could be seen as part of this broader theoretical concept.

With the advent of computer systems, ethics have aroused new interests and dilemmas in society. Terms such as "computer ethics" date back to the 1970s, but ethical dilemmas with reference to the technological environment appear with the development of the first technologies based on computer systems (Wiener 1954, Wiener 1959, Bynum 2001). Norbert Wiener, also considered the father of cybernetics and one of the main contributors to the development of digital computers, recognizes from the early stages of research that technology and digital computers will consistently change many aspects of life and have a crucial ethical importance, anticipating their impact on the labor market.

Today, computer ethics or, in general, digital ethics involves old problems that have acquired a new quality due to digital technology. Simultaneously, there are new dilemmas that did not exist at all, determined by automatic decisionmaking through Artificial Intelligence solutions and the potential risk associated with them (Muller, 2020). Of course, this rapid development of computers and computing in general has raised even more ethical

In a general sense, "digital ethics" has been approached as a need for the study since the first appearances of information and communication technologies. The issue of the need to propose a basis for research and the adoption of digital ethics arises, since the 1970s, where the debates were focused on the fact that "technological civilization" is a truly "new" civilization, in which information and communication technologies play a vital role, growth, hence the recourse to a "new ethics" based on responsibility (Jonas, 2014).

The emergence of new cloud computing technologies, the Internet of Things (IoT), Artificial Intelligence or social media facilitates rapid exposure of products or services to customers, as well as their access to an accessible and diverse market where only trust in the product or bidder can make a difference. Companies have felt the need to reach potential buyers with products much faster, and technology (social media for example) has made this possible.

\subsection{Artificial intelligence and its impact on the business environment}

Researchers refer to Artificial Intelligence as that software's, algorithms, systems, and machines that can demonstrate intelligence (Shankar, 2018). Another way to describe Artificial Intelligence is that this concept does not depend on the characteristic technologies, but rather on the purposes associated with the use and implementation of AI. In this sense, most of the time, business organizations will 
use AI systems to streamline business processes or marketing strategies through easy access of data for more efficient interaction with customers or their own employees (Davenport and Ronanki, 2018). Finally, AI can be described by the ability of a machine or software to mimic human functions, such as reasoning, learning, planning, and creativity. Some AI technologies have been around for over 50 years, but increasing computing power, the availability of huge amounts of data, and new algorithms have led to major advances in AI in recent years. Artificial intelligence is already present in our lives and is considered a central element of the digital transformation of society becoming a priority for the European Union and is expected to bring huge changes to future applications. (European Parliament Resolution 2088-INI, 2019).

As this study explores the ethics of Artificial Intelligence implemented in different businesses, it is important to take a step back and look at what business means for technology in general and for AI. There are different perspectives on the concept of business with respect to business models that can be identified in the literature, most of them are gaining popularity in the 1990s, when companies were using different processes to communicate to investor groups the strategic development ideas for a short time (Zott and Amit, 2010). The scientific literature identifies three main perspectives of the business model concept (Aloini, Latronico and Pellegrini, 2021): the strategic perspective, the one based on the object of activity of the business and the architectural one.

For this paper we consider relevant the third perspective, as this is the most appropriate way for a company to propose a value-added business model (in a broad sense) with the possibility of creating, maintaining, and redistributing this value through digital technologies (in this case Artificial Intelligence). We are talking about a business model digitized by AI systems used to create added value.

Obviously, the relationship between technology and business, in a broad sense, depends on the market context, field of activity, customers and others. Under these circumstances, the main idea of our research is that technology can add value to a business or even create new business models, that focus on added value in all senses (profit, redistribution of it, investment, quality interactions with customers and partners, etc.).

Due to the different forms that AI can take, exploring the impact of these systems on the business environment is a complex process. A recent bibliometric analysis (Loureiro et. al., 2021) in the field of AI applied in business, was performed to obtain a classification of topics of scientific interest, identifying 4 areas of research. 
- the impact of AI on society: this first area covers issues related to how AI influence society (specifically what is the impact of robots, what are the laws that control the effects of AI, how is AI used in marketing and social media to manipulate purchasing decisions)

- the impact of AI on organizations: this area captures the focus of current research on how AI impacts the way we work, factors of production and manufacturing in general, science management, business decisions, and risk management.

- AI methodologies: this topic is dedicated to research aimed at the methods used by AI systems to provide functionality such as prediction, data analysis, learning, neural networking, problem solving.

- AI systems: this area focuses on how AI systems are implemented in organizations such as those that create AI algorithms themselves or those that design products that can incorporate AI or those that only use AI to process information.

Another research topic that is captured from the literature is one related to the impact of $\mathrm{AI}$ in the business environment and we can find research that explores 3 different angles: the impact of AI on the labor market, automation of daily tasks (productivity efficiency) and finally the interaction between companies and customers. (Haenlein and Kaplan, 2020).

In the first category, different studies analyze how the changes introduced by AI influence the way human resources departments are organized (Tambe et. al., 2019) with reference to data storage, decision making, privacy and security and others. Other articles examine how AI systems can streamline business processes by automating daily activities.

Huang, Rust, and Maksimovic (2019) provide a broader view and analyze the relative importance of mechanical activities (e.g., repair and maintenance of equipment), human-thinking (e.g., processing, analysis, and interpreting information) and feeling activities (the feeling tasks such as, communicating with people) in different fields of activity. Analyzing from an empirical perspective, these authors show that, in the future, human employees will be increasingly busy with feeling tasks because the thinking tasks will be replaced by AI systems. They are continuing that hypothesis showing that a similar process happened when the most mechanical loads in the car manufacturing industry were replaced by robots.

Finally, there is the third category of studies focused on the interaction between business environments that use AI and customers (Kumar et. al., 2019). This category focuses on the marketing industry, proposing application models of 
AI through which it can be performed. automating product selection, pricing, or displaying advertising content based on individual customer preferences.

It can be observed that the approach of literature is focused more on the relationship between $\mathrm{AI}$ and the business environment in terms of increasing employee productivity, streamlining distribution chains, optimizing costs, personifying services, without approaching also the potential associated risks of AI solutions.

\subsection{Ethical Perspectives on Artificial Intelligence}

Recent developments in the field of Artificial Intelligence are topics of public debate and attract media attention most of the time. Artificial Intelligence computer systems (whether we are talking about robots, chatbot virtual agents, facial recognition systems, etc.) are perceived as systems that transform from simple computer tools into systems that can make decisions autonomously. Therefore, the scientific community also pays more attention to both studying the development and to identifying the potential impact of these systems.

Nowadays, many companies are reinventing their business processes through digitalization or digital transformation. Referring to the systems of artificial intelligence, it is observed that a universally applicable definition for Artificial Intelligence cannot be found precisely due to the multidisciplinary aspect of the term. Some authors define Artificial Intelligence by the ability of a digital computer or computer-controlled robot to perform tasks commonly associated with intelligent beings. The term is frequently applied to the project of developing systems endowed with intellectual processes characteristic of people, such as the ability to reason, to discover meaning, to generalize or to learn from experience (Copeland, 2020).

Alternatively, some programs have reached the performance levels of human experts and professionals in performing certain specific tasks, so artificial intelligence in this limited sense is found in applications as diverse as medical diagnosis, computer search engines and recognition. voice or handwriting. Artificial Intelligence or in general sense, the theory of developing "computing" systems that can perform activities specific to human intelligence, is considered an ongoing revolution that transform societies and science (Harari, 2017).

While some forms of Artificial Intelligence (such as machine learning, deep learning, artificial neural networks) are changing the way data are stored, accessed, and processed other forms, such as autonomous and semi-autonomous systems are increasingly used by to different industries: medicine, transport, production. (Jordan, Mitchell, 2015). Of course, the benefits for optimizing work processes and 
business productivity have been positively influenced, but on the other hand in the scientific environment there have been concerns that Artificial Intelligence would endanger jobs (Nature editorial, October 2017) or could be used as malicious tendencies (Brundage et al., 2018), or would exclude liability as there is a risk of inadvertently disseminating prejudices that may undermine the idea of fairness (Zou and Schiebinger, 2018). Other studies aimed to identify parameters to assess the ethics of Artificial Intelligence (Cath et. al., 2018, Greene et. al., 2019) or its association with some systemic risks (Crawford and Calo, 2016, Altman et al., 2018) which can generate negative consequences in society such as discrimination due to the prejudice of algorithms (Bolukbasi et al., 2016, Veale and Binns, 2017).

In the last decade, the private sector has made massive investments in innovation by developing robots and autonomous Artificial Intelligence systems that can interact with humans in various fields of activity. These innovations of recent years undoubtedly have benefits for society because they can save time, reduce human effort, costs or even save lives (Winfield and Jirotka, 2018).

For this paper, we considered essential to study the business perspective when talking about AI. Among others, there are also many signs from the business field indicating the Artificial Intelligence solutions are used to transform business processes to streamline productivity and reduce costs. First, to automate business processes, AI systems use programmed algorithms to perform well-defined tasks without the need for human intervention. Some examples of this could be related to automatic transfer of data from emails to centralized storage systems, automatic replacement of lost bank cards, automatic implementation of simple financial transactions or reading documents to be able to automatically extract keywords by language processing natural language processing.

Alternatively, AI systems can identify key information from large volumes of customer data, using not only available figures from their transactions but also from elements such as texts, messages, voice, facial recognition, and images. Using analytical features associated with Artificial Intelligence systems, companies can make predictions about customer preferences, detect real-time fraud, or implement digital advertising campaigns that target customers in real time (Davenport et al., 2020).

Different studies reveal that AI solutions improve process of decisionmaking, while boosting the human analytical skills and decision-making abilities, and improving human creativity (Wilson \& Daugherty, 2018). However other researchers such as Miller (2018) advertise the need of a new human-machine symbiosis and calls for the rethink of "how humans and machines need to work symbiotically to augment and enhance each other's capabilities". In this context, 
ethical dilemmas concerns are on an increasing trend, and we are witnessing not only the research of scientific concepts but also the assessment of the impact in terms of ethics applied to artificial intelligence systems.

In recent years (after 2014), private companies, research institutions, as well as public sector organizations have formalized principles and guidelines for the ethics of Artificial Intelligence, but nevertheless there is still a strong debate about what Artificial Intelligence really means and what it is the requirements, technical standards and good practices that can ensure this ethic (Jobin et. al., 2019; Mittelstadt, 2019).

Also, national, and international organizations, both governmental and nongovernmental, have responded to these social fears by developing new directives or ad-hoc committees with Artificial Intelligence experts which aims to design policies that represent legal bases for controlling AI systems ethically. The European Commission, the Organization for Economic Development and Cooperation (OECD), the Singapore Council for the Ethical Use of Artificial Intelligence and Data, or the UK Parliament's Artificial Intelligence Committees are just a few examples of international bodies whose role is to set rules to ensure AI ethics (Jobin et al., 2019). Added to this effort are some private companies that produce Artificial Intelligence solutions such as SAP, Google in 2018 or Microsoft that have publicly released codes of ethics, principles, and standards of Artificial Intelligence solutions (Microsoft, 2017, SAP, 2018, Google, 2017). Therefore, this paper will highlight the main topics and key players that are currently part of the $\mathrm{AI}$ ethics in business debate.

The scientific communities approach AI ethics from different perspectives, associating this with the ethics of other fields. Recently, there have been several comparisons and possible associations between Artificial Intelligence ethics initiatives and medical ethics. (Whittlestone et al., 2019). Studies have demonstrated that one starting point in the research of AI ethics could be to refer the ethical guidelines needed in AI with the classical principles applied in medical ethics. (Floridi, 2018).

The OECD and the European Commission have expressed their support in this regard (OECD 2019 and EU 2019) and have proposed four principles that will contribute to the development of "trustworthy" Artificial Intelligence solutions: respect for the autonomy of the individual, injury prevention, fairness, and explicability. This assimilation of AI ethics around the principles of medical ethics is probably the most pragmatic approach historically. This has emerged in the medical field and can be perceived as a theoretical moral framework. 
These four essential principles need to be always contextualized, depending on different decision-making situations and different fields of activity (BeauChamp and Childress, 2009). AI needs a similar approach in terms of founding a common framework to ensure ethics guidelines, as in medical ethics, the principled approach provides a common language for identifying and conceptualizing ethical challenges by identifying concrete solutions for health policy making and clinical decision making (Bosk, 2010).

A similar principled approach in AI ethics seems to aim incorporating normative considerations in the design and governance of technology. (Mittelstadt, 2019). This type of approach, provide a useful framework for assessing the potential for Artificial Intelligence ethics to promote real change in the development and implementation of these solutions. Despite the initial credibility offered by the comparison with medical ethics, there are reasons to be concerned about the future impact of AI ethics because there are important differences between medicine (or other traditional professions (Filipovic et. al., 2018)) and AI development.

Note that in the scientific community we identify a consensus according to which Artificial Intelligence should be ethical, but nevertheless there are significant divergences when discussing the framework, principles, and control of AI ethics. Moreover, there is some uncertainty about how ethical principles and guidelines should be applied when developing or implementing AI solutions. Thus, contrary to the scientific consensus on the need for ethics, many challenges are related more to the implementation, control by political legislation and governance of AI technologies, there is an imperative need to harmonize and re-prioritize the AI agenda involving both business organizations as well as the governmental environment (Jobin et al., 2019).

But in this sense, the major challenge is that the development of a global agenda of AI ethics must also consider respect for cultural diversity and transnational moral pluralism. The ethics of Artificial Intelligence systems can be correlated with the degree of trust of the consumer public. Building such trust in AI requires different ethical approaches to target individual systems themselves and areas of applicability (Robinette, Wagner, Howard, 2013), but also to respect an institutional framework.

In this regard, Winfield and Jirotka (2018) argue that one of the necessary (but not sufficient) elements to build trust in AI systems is to ensure a framework of "ethical governance" (AI). The two define this concept as that set of processes, procedures, cultures and defining values to ensure the highest behavioral standards for Artificial Intelligence systems. It is therefore proposed to move from a 
descriptive ethic in which AI solutions are evaluated to a normative, prescriptive ethic with a role in framing the principles of responsibility in research and technological innovation.

The goal of ethics is to address fundamental issues related to practical decision-making, and one of the major concerns may be the evaluation of standards by which human actions can be judged rightly or wrongly.

We explored on the different approaches of the AI ethics with applicability on business organizations, within the next sections of this paper we will focus on the bibliometric analyze to understand what the most relevant studies, authors and key topics are, as well as what will be the further research opportunities within this field. The specific interest for this paper was to use the bibliometric techniques to explore the field of AI ethics in business. Based on the above context, we aim to identify the further research opportunities on how business organizations are perceiving the AI ethics, while using it to digital transformation and business optimization.

\section{DAtASETS AND Methodology}

In this section we will describe the strategy used on this paper that led us to the identification of the main datasets that served as input for the bibliometric analysis, and the bibliometric methods that were used in the analysis.

\subsection{Data sets}

Bibliometric analyses are popular today among scientific researchers and this is mainly because it represents a great instrument that allows to explore large volumes of scientific data, that could be assessed to identify emerging trends in literature, collaboration patterns or research components. (Donthu et. al., 2021). On the AI research topics, there are several others recent bibliometric analysis, but either covering general aspects of ethics and privacy (Zhang et. al., 2021), either focusing on general evolution of AI (Yuh-Shan and Ming-Huang, 2020; Yufei and Zhongbao, 2019) or niched on specific domains such as healthcare (Guo et al. 2020; Vinit and Saikat, 2020) or education (Song and Xiang, 2020; Baek and Doleck, 2020).

For this paper, we used Scopus as our primary datasets resource, because this is a well-known platform of bibliometric data sources and the largest database that provides scientific literature content, having a global presence and covering a variety of research fields. 
In the first phase, our research explored the global landscape of AI Ethics in business, and hence we had the following strategy of exploring the relevant data that allowed us to \#1) identify all relevant articles for the chosen topic so that we can analyze the overall results, and \#2) have a niche approach by refining to identify only the documents that are article type and written in English and \#3) filter on most cited 2000 articles that will use for the actual bibliometric analyze.

The search strategy used for the initial discovery of the chosen topic was the below one, and that was performed between $15^{\text {th }}$ of May and $04^{\text {th }}$ of June 2021 with below data sets results(\#R)

\begin{tabular}{lll}
\hline Dataset & Results(\#R) & Search String \\
\hline$\# 1$ (relevant & 16822 & ALL ("Artificial Intelligence" AND ethic* AND business ) \\
articles) & & \\
\hdashline$\# 2$ (refining) & $8942-$ & ALL ("Artificial Intelligence" AND ethic* AND business ) \\
& & AND ( LIMIT-TO ( DOCTYPE, "ar" ) ) AND ( LIMIT- \\
& TO (LANGUAGE, "English")
\end{tabular}

\#3 (filter) $2000 \quad$ On dataset \#2 - filter on first 2000 most cited

Based on the above, there were 3 main datasets identified as following:

- dataset \#1) which is initial raw dataset (16822 documents) obtained as per the above search string.

- dataset \#2) which was used after refining the results because this paper focused only the articles as document type that were written in English.

- dataset \#3) which was the working dataset for the bibliometric analysis obtained after filtering the second dataset on first 2000 most cited articles as per Scopus indexation.

Considering this search strategy, we can see in Figure 1, that the first identified article was published in 1972, focusing the need of theorizing societal cybernetics to have a proactive control on computer machines and Artificial Intelligence (Byrne, 1972). Between 1972 and 2016 we can see a low rate of studies and starting with 2019 we can observe an abrupt rise of published articles which indicates an urgent need for attention from the academia on our research topic. 
Documents by year

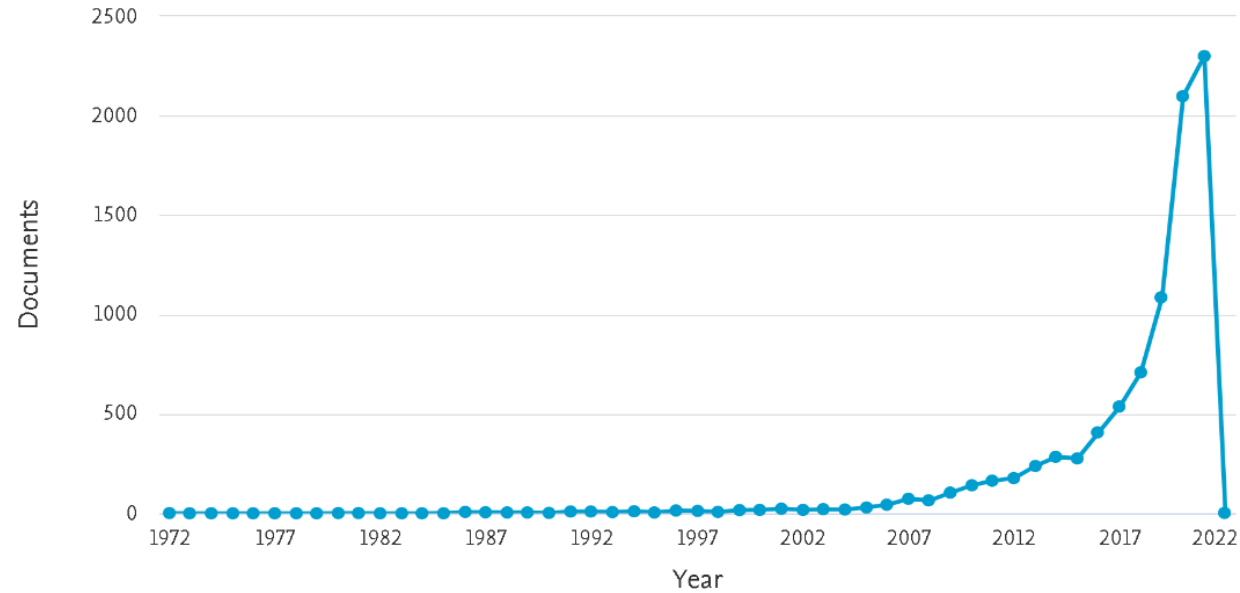

Figure 1 Trends in the annual number of records as per the search strategy using dataset \#2

Based on the Figure 1, we can see that after year 2000 there was a particular interest from the academia on the AI ethics topics. That could be correlated with the fact that in same period the AI solution faced a boom and its evolution trough new developments such as machine learning, deep learning, neuronal networks but also the tremendous growth of the computer transistors. (Delipetrev et. al., 2020). The fact that within the last two decades we can see an increasing number of publications in journals, could be related to the fact that the AI does not anymore representing some ideations models, but offers specific solutions for an era which is data driven. Additionally, not only the academia is interested in these topics, but also the international organizations or the companies producing AI systems.

\subsection{Methodology}

The research approach for this paper is schematically described in Figure 2 Essentially, we had two big phases that we used to explore the topic of AI ethics within the business context so that we can identify key concepts, current concerns and issues presented in previous research. In the Phase 1 we focused on identifying the right datasets that can be used in our analyze, while in Phase 2 we focused on the bibliometric techniques that can be used to have an analytic approach on the identified results. 
Phase 1. Datasets processing

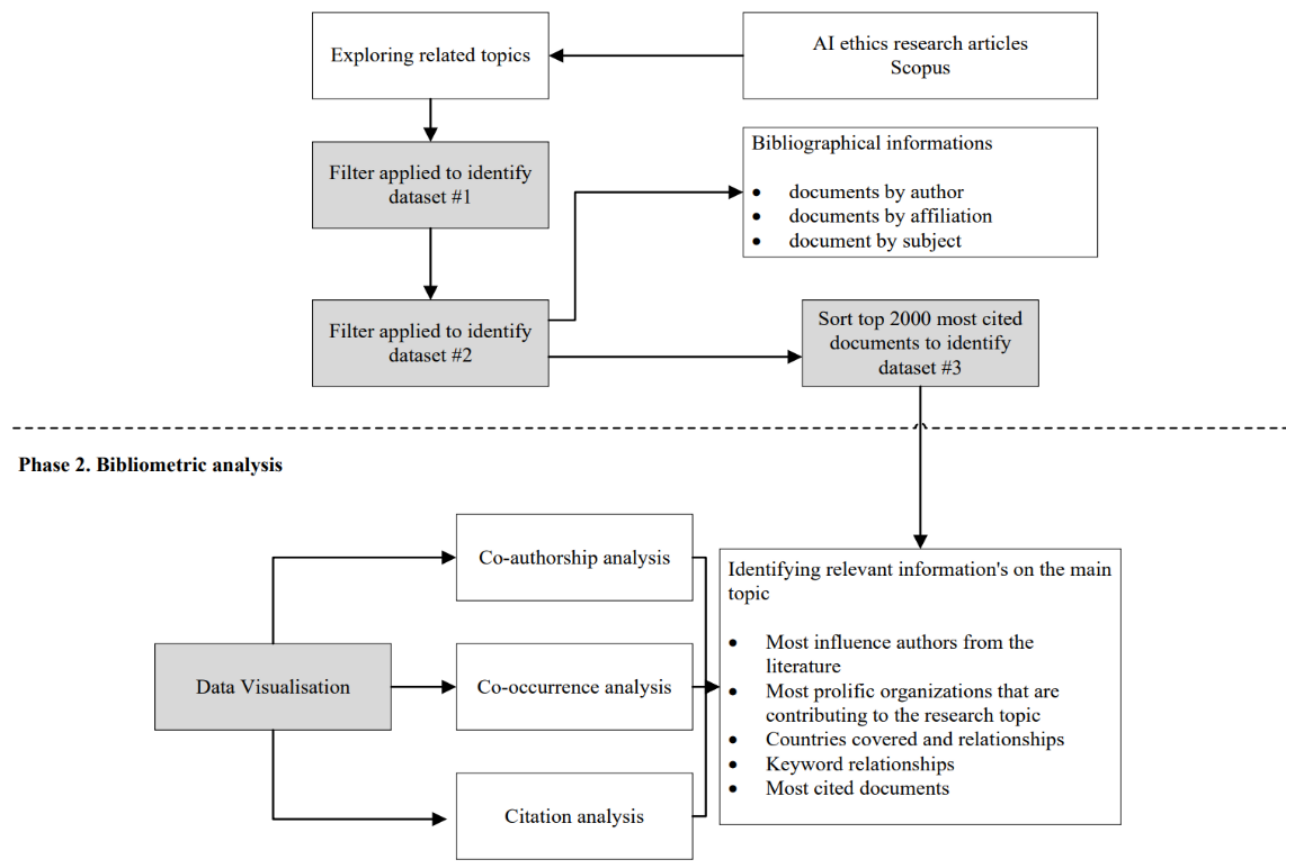

Figure 2. Research framework on understanding the AI ethics in business

\subsubsection{Phase 1 data processing}

In the first phase of our study, we focused on exploring the main articles related to AI ethics in business and therefore we applied the above-described search strings to identify the datasets \#1 and \#2. One important mention to make here is that, even though in dataset \#2 we identified 8942 related articles, we only exported the first 2000 most cited documents. That was since currently in Scopus there is a hardcoded limitation that allows the full information export of only first 2000 identified articles. Having this limitation, we obtained a new dataset \#3 that will be used for the bibliometric analysis. Because the study focuses on obtaining a high-level overview on all the identified articles for the chosen topic, we used both datasets \#2 and \#3 as per below:

- dataset \#2 was used to explore the overall bibliographical information, analyzing all articles authors, affiliations and subject and,

- dataset \#3 was used for the bibliometric analysis. 


\subsubsection{Bibliometric analysis techniques}

Once identified the dataset \#3, we used this one for the bibliometric analysis, focusing on data visualization. Specifically, we performed 3 types of analysis via VOSviewer. VOSviewer is a software tool for constructing and visualizing bibliometric networks. These networks may for instance include journals, researchers, or individual publications, and they can be constructed based on citation, bibliographic coupling, co-citation, or co-authorship relations. (VOSviewer, 2021). For this paper, VOSviewer was used for data visualization, focusing on three main analysis categories: co-authorship (to identify most relevant authors, organizations, and countries), cooccurrence (to identify most relevant key words), and citation (to have a look on most relevant documents). Based on this methodological approach, this paper offers a consistent view on the current issues and concerns related to AI ethics in business, which may provide a certain level of knowledge that can further help other researchers to shape their studies with respect to AI ethics and impact on business landscape.

\section{RESULTS}

We investigated the AI ethics in the business field, by exploring all the articles and indexed by Scopus within the last years (as detailed in our search strategy in Figure 1) so that we can identify who are the key players (e.g., research institutions and universities, countries, subjects) contributing to this research domain, but also to capture what is the overall interest of the academia in these issues and how this changed over time. From a result analyze perspective, this paper focus on mixing results from the bibliographical information and data visualization techniques so that will offer a consolidated view on the research topic, assuring the correlation between the different types of data analyzed (essentially between datasets \#2 and \#3).

\subsection{Key contributors on the research field of AI ethics in business}

For this research, we considered relevant to utilize the full bibliographical information (as per Scopus definition) applied on the dataset \#2 results, with the scope of revealing who are the key players that are contributing to the research of AI ethics in business. Specifically, we focused on analyzing 1) what are the top 15 authors and how many articles they published, 2) what are the top 15 academical organizations that are considering the research of the chosen topic and 3) what are the main subject's areas of research where the topic of AI ethics is present. As side note it is important to mention that we always choose the first 15 authors and 
organizations, because that is the maximum default value that can be displayed by Scopus within the search results analyze.

The below Figure 3 lists the top 15 most productive authors as per our search strategy, with Maseleno Andino the biggest contributor with 27 articles, followed by Huda Mitchel with 26 articles identified, Dwivedi Y.K., Chatterjee Sheshadri, Floridi Luciano and other as per below. One important aspect to mention here is that Maseleno (the most prolific author identified) is not always the first author, and he is a contributor to AI related research focusing more on technical aspects (methods, code, and development techniques) with applicability on different industries, such as pharmacy (Irawan et. al, 2019), food industry (Hamid et. al, 2018) or education (Abadi et. al, 2018). On the other side, other authors have a multidisciplinary approach on AI ethics topics (e.g., Huda and Dwivedi), or they are referring to the impact of AI in business organizations (e.g., Chatterjee, Abadi, Connelly), or to the general need to regulate the AI by assuring its ethics via a strategical framework (e.g., Floridi, Taddeo).

According to this output, we can see that the researchers are covering a large spectrum of AI studies but with not much applicability on the AI ethics impact on business, and if there are studies on that, those are presenting a generic approach (Dwivedi, 2021). This may indicate a good opportunity of researching the AI ethics impact on business with applicability on why we need such studies, who are the key players that should trigger this and what could be the consequences in case of missing such research.

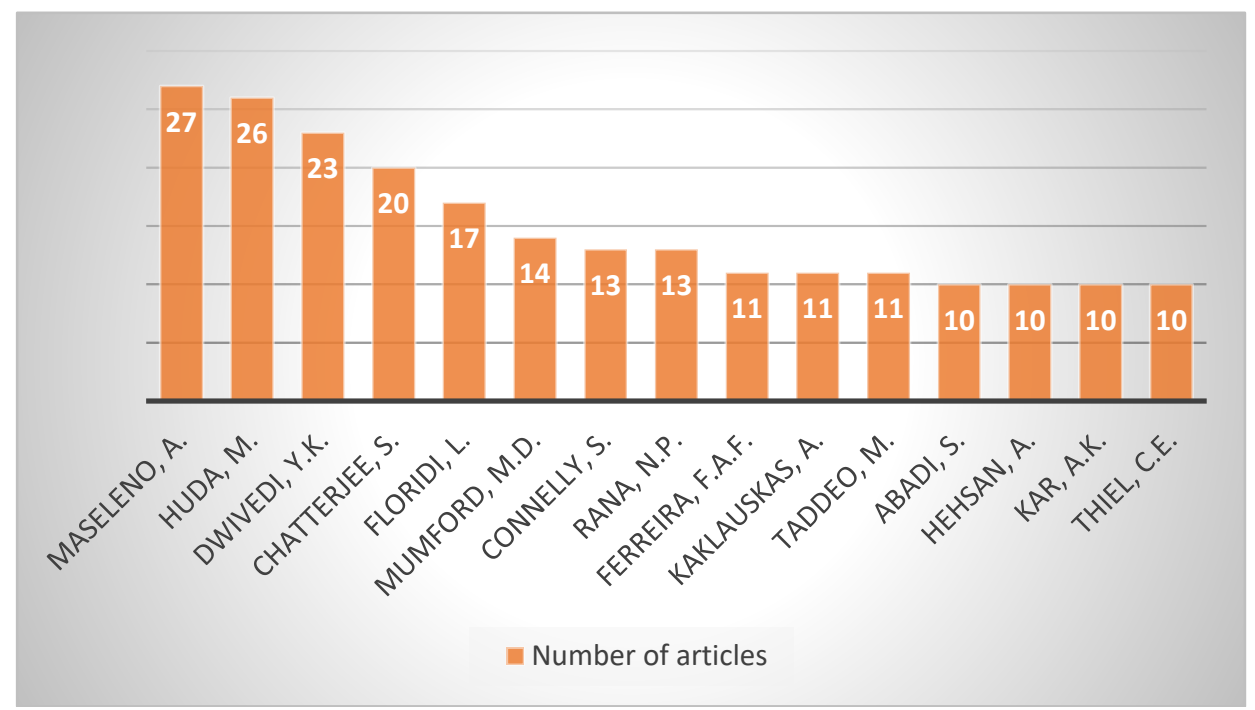

Figure 3 Top authors contributing to the research field as per dataset \#2 
On the other side on Figure 4, we can see a network map on co-authorship extracted with VOSviewer. Among the first captured aspects, we can see a big cluster formed around the authors Maseleno and Huda, which seem to be the most influential and prolific authors on this research topic, but their scientific approaches are rather generalized with respect to AI. Additionally, another important cluster seems to be the one formed around authors such as Mumford, Connelly, Thiel and Devenport, which are targeting case-based ethics (Bagdasarov et. al, 2013) within their articles. That could be an important aspect indicating that a further potential research opportunity around the AI ethics in business will consist of a case-based approach (like ethics in medicine or in journalism etc.). Furthermore, another important co-authorship cluster revealed by VOSviewer is around authors such as Dwivedi and Floridi. Note that all identified articles from Floridi, are in coauthorship with Taddeo, but their articles are tackling specifically the need for AI ethics in all domains (a generic approach).

One preliminary key conclusion on the authors and co-authorship analyses could be that it looks like there are two big categories of authors. In the first category, we have those authors that are researching the ethics of AI from a technical perspective, while targeting different industries that implemented specific AI solutions for optimizations of different processes. In the second one, we can retrieve researchers that are focused on the need of AI ethics in all domains, working on finding solutions/framework that could answer issues and concerns generated by AI. Hence, one future research direction could be to map the need of an AI ethics framework in business with respect to the impact that AI can generate for both business landscape and its consumers. 


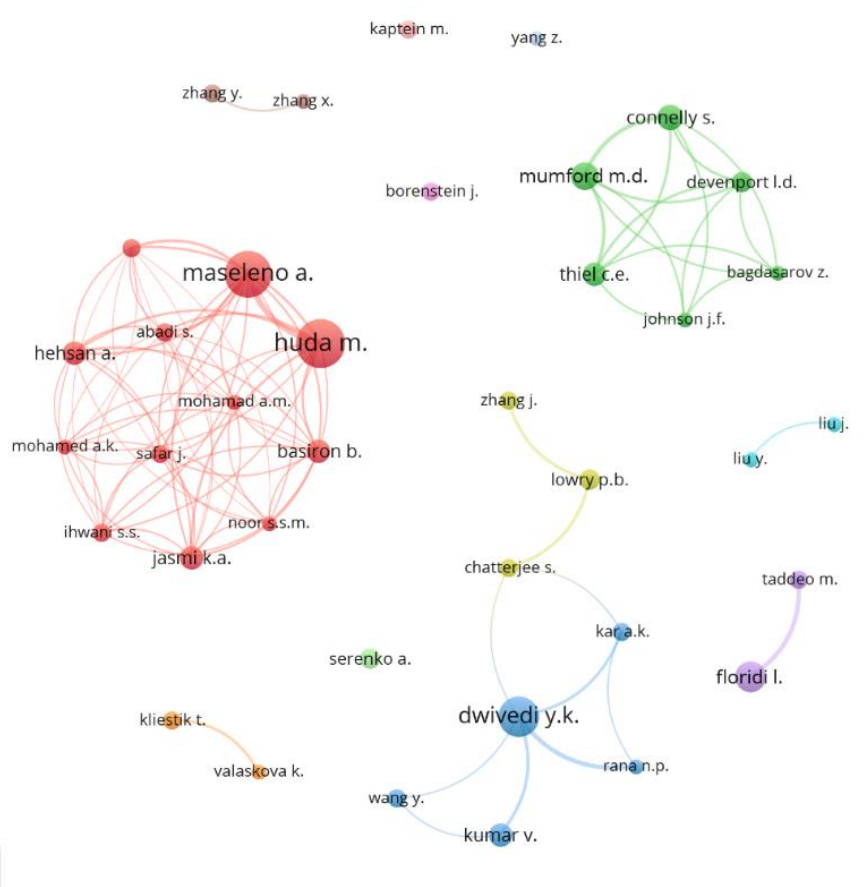

Figure 4 Co-authorship (author based) map extracted with VOSviewer based on dataset \#3

Another interest on this study is to identify the most representative institutions that are contributing to the research of AI ethics in business topics. The Figure5 list the first 15 documents affiliations as per our identified dataset \# 2. That means, based on the bibliographical information obtained in dataset \#2(8942 articles), University of Oxford and University of Delft seems to be the most prolific ones on the research topic of AI ethics and business. These are followed by University of Twente, University of Amsterdam, University of Malaysia, University of Queensland and others (each of them with a similar number of research). It is not a random result that the first two most influential institutions are leading the research contribution on this chart (based on the affiliation of the indexed articles in Scopus), since these organizations are incorporating digital ethics labs (see Oxford Digital Ethics Lab, or Digital Society Institute at University of Twente).

One key element that can be observed based on this finding is that the organizations that have dedicated AI research departments are tempting to contribute more to the overall research on AI ethics and its associated impact in different domains of activity. Additionally, 13 of 15 of these universities are part of 
the top 200 World Universities ranking for year 2021 (QS World University Rankings, 2021). In Table 1, we centralized the 13 of the 15 universities contributing to AI ethics in business research as per the result analysis on dataset \#2. There are two exceptions here: one is CNRS in France which is not a university and the other one which is the Queensland University of Technology that is ranked on the position 217 on the above-mentioned ranking top.

An important aspect to be mentioned is that within the overall score obtained by each university in the above-mentioned ranking, there are 2 ratings out of 4 contributing the most: the academic reputation (40\%) and the citations per faculty (20\%). The academic reputation is a score obtained after a survey that collates the expert opinions of 130.000 individuals in the higher education with regards to teaching and research quality in the universities. The citations per faculty is an indicator that is calculated based on the total number of citations received by all papers produces by an institution across a five-year period. In Table 1 both ratings are listed for each university just to exemplify the reason why the intuitions that are contributing the most to the research of AI ethics in business are also part of the top 200 most valuable institutions.

\section{Number of articles by institution}

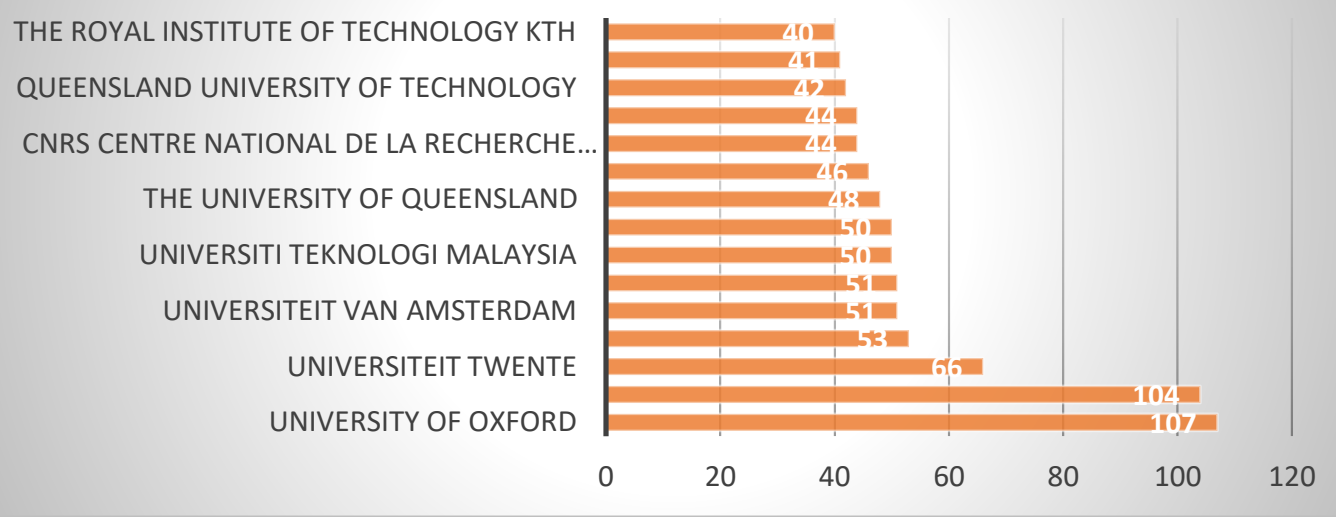

Figure 5 Top academical institutions contributing to the research field as per dataset \#2

Table 1 Ranking in QS World University Top for the most representative institutions identified in dataset \#2

\begin{tabular}{|c|l|c|c|}
\hline $\begin{array}{c}\text { Rank in QS } \\
\text { World University }\end{array}$ & \multicolumn{1}{|c|}{ University } & $\begin{array}{c}\text { Academic } \\
\text { Reputation rating }\end{array}$ & $\begin{array}{c}\text { Citations per } \\
\text { faculty rating }\end{array}$ \\
\hline 5 & University of Oxford & 100 & 99.4 \\
\hline 197 & University of Twente & 96.1 & 86.5 \\
\hline
\end{tabular}




\begin{tabular}{|c|l|c|c|}
\hline $\begin{array}{c}\text { Rank in QS } \\
\text { World University }\end{array}$ & \multicolumn{1}{|c|}{ University } & $\begin{array}{c}\text { Academic } \\
\text { Reputation rating }\end{array}$ & $\begin{array}{c}\text { Citations per } \\
\text { faculty rating }\end{array}$ \\
\hline 61 & University of Amsterdam & 84.5 & 61.6 \\
\hline 57 & Delft University of Technology & 70.7 & 75.8 \\
\hline 7 & University of Cambridge & 100 & 69.2 \\
\hline 40 & The university of Sydney & 97.4 & 69.6 \\
\hline 187 & Universiti Teknologi Malaysia & 39.4 & 51.6 \\
\hline 10 & University College London & 99.4 & 65.4 \\
\hline 46 & The University of Queensland & 89 & 79.6 \\
\hline 25 & University of Toronto & 99.3 & 45.8 \\
\hline 2 & Stanford University & 100 & 98.1 \\
\hline 120 & $\begin{array}{l}\text { Eindhoven University of } \\
\text { Technology }\end{array}$ & 30 & 76.6 \\
\hline 98 & $\begin{array}{l}\text { KTH Royal Institute of } \\
\text { Technology }\end{array}$ & 46.2 & 68 \\
\hline & & & \\
\hline
\end{tabular}

On the other side, on Figure 6, we can see a map extracted from VOSviewer using the dataset \#3 (most cited 2000 articles), that is listing the co-authorship connections of the most influential organizations. To obtain this result we configured VOSviewer to display the organization with minimum 3 articles published on the selected research topic so that we can make it relevant. One important finding here is that the academical institutions with more prolific research (Oxford, Twente, Amsterdam) are not involved on co-authorship contributions. In other words, the researchers affiliated to these institutions published their results without collaborations with other institutions within EU or outside EU. Additionally, we can observe a big cluster of academic institutions that are researching this topic in a collaborative approach, formed around University of Malaysia, but this looks like a silo research Asia based.

One key observation related to the current published research is that these are not spanning a cross-cultural approach on AI ethics. There are silos of organizations whit affiliated researchers that are not necessarily have crosscollaborations. The key pattern on this matter seems to be a domestic collaboration. Essentially when ethics in general and AI ethics needs to be research it is mandatory to have as pre-requisites the cross-cultural differences because that could be an important corner stone in deciding how AI solutions could be ethically implemented to have ethics decision-making processes (Hagerty and Rubinov, 2019; Narayanan, 2021). 
university of helsinki, finlan

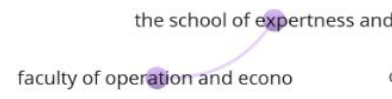

oxford internet institute, un

department of management studi

emerging markets research cent

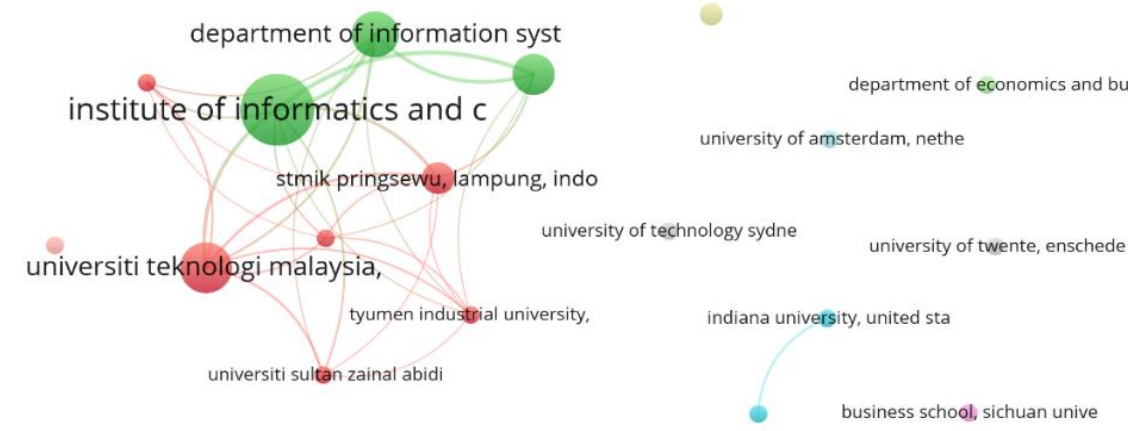

graduate school of business, $s$

arizona state University, unit

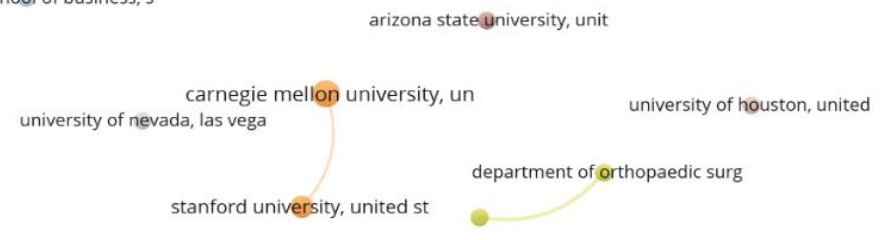

vosviewer

Figure 6 Co-authorship (organization based) map extracted with VOSviewer based on dataset \#3

Furthermore, our paper captured the co-authorship network visualization map based on countries (Figure 7). We can clearly see two big pols around the English-speaking countries: United States (614 publications) and United Kingdom (263 publications). As a side note, for this paper we configured VOSviewer to display only countries that have a minimum of 30 publication so that we can make this relevant for further research.

Also, there are other countries such as Germany, Netherlands, Australia, Taiwan, Malaysia, China, Canada, Italy with a significant number or published articles too (around 100 each). The following observations can be made: (1) the USA and UK dominates the total number of relevant articles; (2) other Englishspeaking countries Australia, and Canada have also strong interest in AI ethics; (3) China and other Asian countries such as Taiwan, India, Vietnam, South Korea, Malaysia are also well ranked and there is a strong collaboration between them; (4) comparably, European countries, such as Germany, the Netherlands, Italy, Spain, and France, produce a large volume of research together as an single entity. As noticed also on the analysis of the co-authorship based on institution, it looks like 
there is a strong interest in each of the displayed countries but the hey pattern in terms of collaboration is the domestic one or maximum a regional one (looking at the EU or the Asian countries).

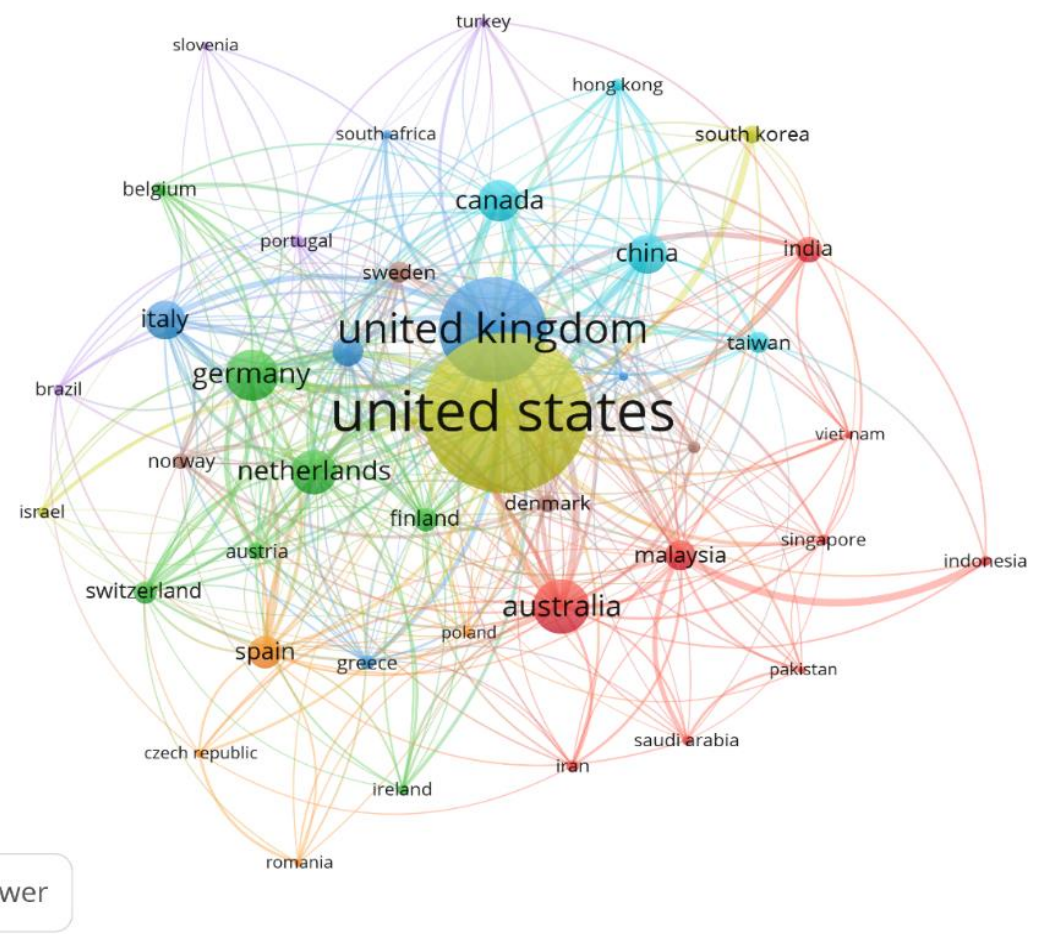

Figure 7 Co-authorship (country based) map extracted with VOSviewer based on dataset \#3

As a preliminary conclusion, we identified the key players (e.g., academic institution, and most prolific authors and communities) which are significant contributors to the research undertaken in their countries on AI ethics in business. Also, one important finding was to understand the current cross-collaborations between these players so that we can understand the relationships between these research topics. Such information's could help us to design a clear landscape of the current state of the AI ethics in business research agenda, understanding who's having a strong interest within this area, how is that objectified, what are the current gaps and what further study opportunities may be developed. 


\subsection{AI ethics and the main subject areas of interest}

The aim of this paper was to explore what's the current research agenda on the AI ethics applied to different business models, so that we can further develop studies on the impact of AI from an ethical perspective and how organizations can use frameworks with the scope of assuring the ethics of the decision-making of AI solutions. Hence on the results analysis, this paper captures also the main subject areas and the most important keyword that are currently mentioned on the identified articles.

In this section we moved our focus again on the dataset \#2 to understand, from bibliographical information available in Scopus, what are the research subject's areas of the articles identified as per our initial search string. In the Figure 8 we have listed all the subject areas that are incorporating the identified articles.

Documents by subject area

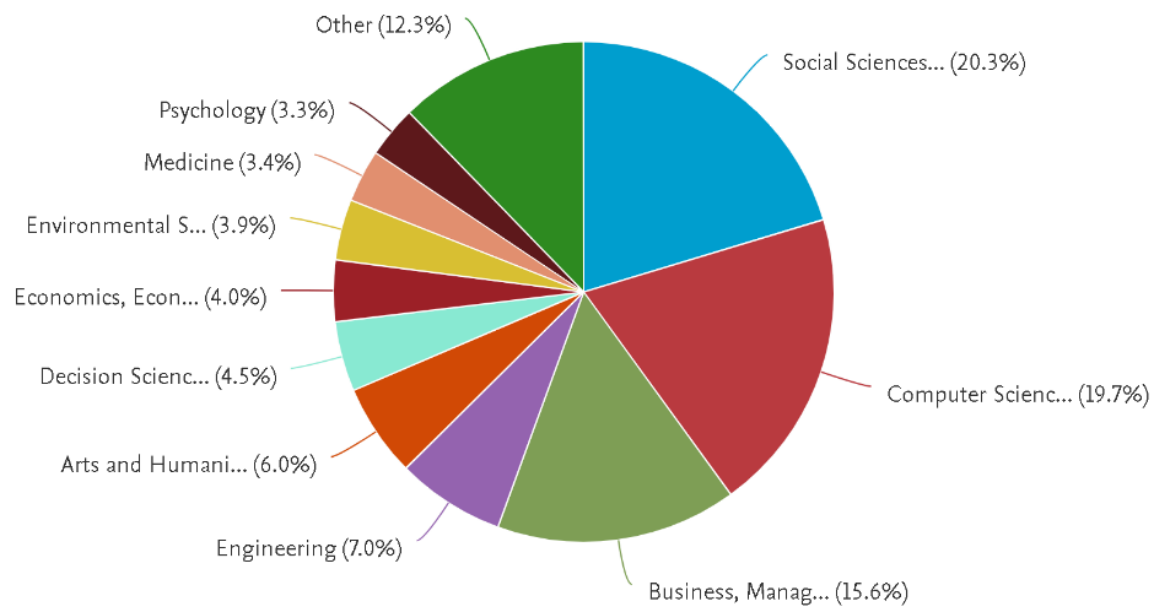

Figure 8 Documents classified by subject area extracted from Scopus using dataset \#2

The following observations can be made: (1) most part of the articles are incorporated into the Social Sciences area - 3670 documents wile 3551 documents are part of the Computer Science research area and 2807 are part of the Business, Management and Accounting area; (2) there is an strong research interest on AI ethics that is coming from the philosophical approach and that is explain the Social Sciences have most part of the listed documents and (3) engineering research area have only 1266 indexed documents which may indicate a lack of interest within the AI ethics at its design/development level. 
It is essential to explore AI ethics not only from a philosophical and conceptual point of view, but it is equally important to do this also from an engineering perspective (to explore the ethics of the code and the algorithms that are the foundation of the AI solutions).

On Figure 9 we have the keywords identified with VOSviewer by using a minimum of 25 occurrences per word so that we can keep this research relevant. In bibliometrics paper, the keywork analyses is considered as a crucial element that can help identifying the core concepts by revealing the structure of the research domains (Su\&Lee, 2010). This approach was also used on this paper so that we can understand what the most important topics of discussion are: main issues and concerns surrounding the AI ethics topics and business. Unexpectedly, the first observation is that the keyword business is not present at all within the identified key words. From the below map we can distinguish 4 main clusters that are distributed as following:

\#Cluster 1 formed around the keyword Artificial Intelligence in strong relationship with other words (a smaller occurrences), such as: machine learning, algorithms, sustainability, trust, economics, data privacy, big data, security. This could indicate an interest from the researchers that are approaching the AI ethics topics from the perspective of security, data privacy and compliancy.

\#Cluster 2 formed around the word Decision Making correlated with other relevant keywords, such as Internet of Things, Blockchain, social media, commerce, information management, sustainable development. This cluster may reveal the fact that there is a strong interest in re-defining the business decision-making processes trough the AI technologies.

\#Cluster 3 formed around the word Ethics. This is a smaller cluster consisting of words such as robotics, automation, philosophical aspects and point out an interest of the research on ethical concerns around the new technological ways that can be used to automate routine tasks of human beings.

\#Cluster 4 formed around the word Human and connected with other words such as methodology, internet, research, algorithms and with privacy, security, and development. This last cluster could indicate that the researchers are always put the individual in the center of everything. At the end, the technology should be made for the people and that could indicate a concern coming from the academia that there could be risks associated if AI is not designed for people assuring the needed ethics. 


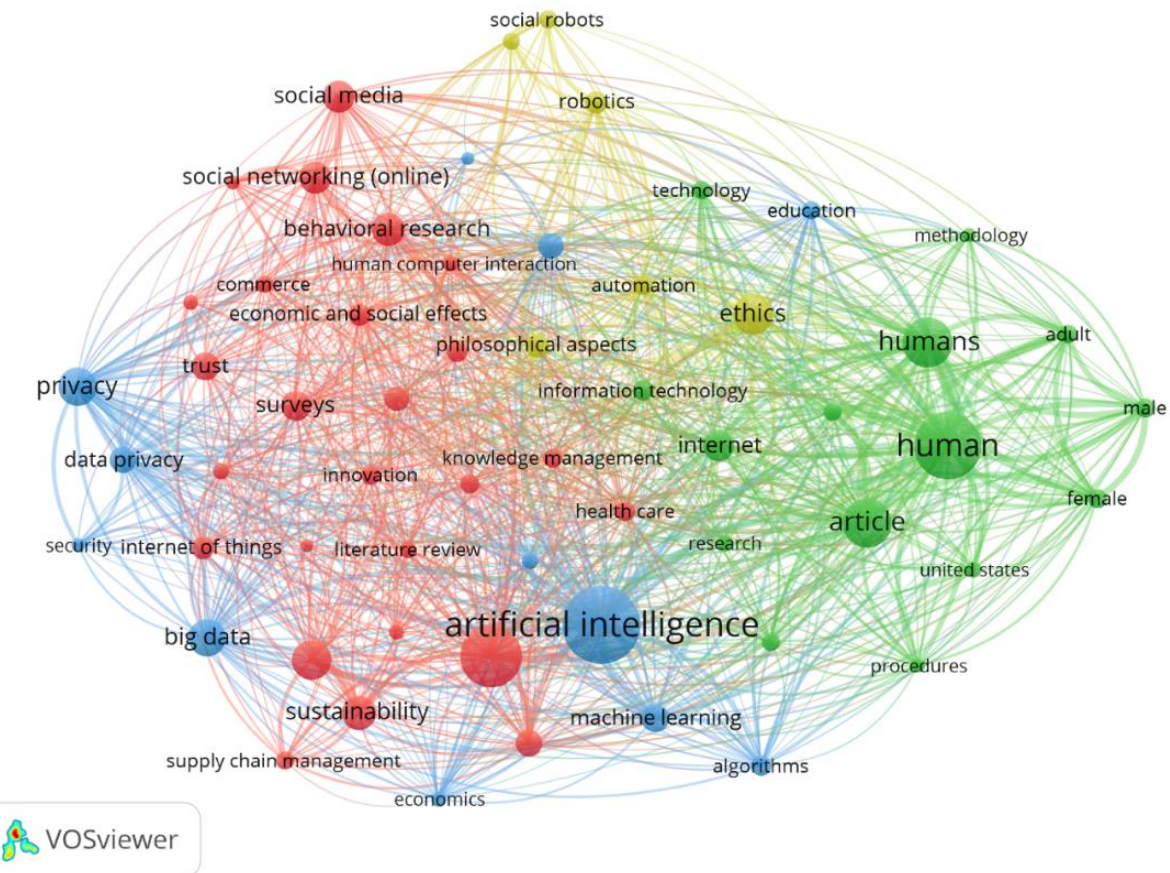

Figure 9 Co-occurrence analysis on keywords extracted from VOSviewer using dataset \#3

Based on the above findings, it looks like the current emerging issues in AI ethics in business are related to topics such as data security and privacy, economic and social impact, automations and robots and human beings. There is a strong indication that topics such as technology and subsequently artificial intelligence, big data, and autonomous systems (i.e., robots, self-driving cars) are questioned from the perspective of their impact on humans, economy, and society. These debates are clearly reflecting the current dilemmas that are researched and questioned by the researchers.

As a conclusion, the above identified keywords as well as subject areas of research help us to understand that there is a strong need in continuing to explore the AI ethics in a general sense, but also to explore specific domains (i.e., business area and how we can assure the AI ethics for sustainable business decisionmaking). We can conclude that there seems to be a research opportunity on specific niches that need to address the AI ethics in business and the associated implications. In other words, some of the future research directions could be to understand how and with what purposes the business organizations are using the AI 
solutions, how ready are they to work with these and what could be the associated ethical risks and the mitigation solutions available.

\section{CONCLUSIONS}

In this article we analyzed the most 2000 cited articles from Scopus database as per the described search strategy, using a series of co-authorship and cooccurrences bibliometric analysis, with the scope of investigating the current debates around the AI ethics in business. The motivation for such research was partially due to the fact we are seeing an accelerated development of AI systems used for business optimizations, and partially because we can see an increased interest and concern coming from the public but also from the academia. This paper's aim was to understand to which extent we need to research on AI ethics in business. The objectives were to identify the key players (authors and institutions) using co-authorship bibliometric analysis, as well as the main topics and current emerging issues. This paper referred on the most prolific authors and their affiliations, countries and research institutions which have the highest contribution to the research on AI ethics in business. Besides these, our research highlights the main topics and subject areas that are presented in the current debates. At the same time, this paper established further research opportunities that may arise. Such findings, revealing a quantitative picture of the current landscape of AI ethics in business research, could be relevant to scientific communities and to business decision makers, but also to other audiences, such as policy makers, IT representatives and government agencies.

\subsection{Our key findings}

Referring to the key findings of this paper, we can see that the most prolific authors (Maseleno Andino-27 articles, Huda Mitchel-26, Dwivedi Y.K. - 23, Floridi L - 17) are covering a broad range of research topics but from a conceptual point of view. These topics are mainly related to 1) technical implications of AI systems in different industries; 2) the need of having regulations and frameworks to be used to assure an AI ethical governance; 3) the multidisciplinary perspectives that can be associated with $\mathrm{AI}$ systems and the potential risks.

According to this output, we can see that the researchers are covering a large spectrum of AI studies but with not much applicability on the AI ethics impact on business. Furthermore, this research distinguished between two big categories of authors. In first category we have those authors that are researching the ethics of AI 
from a technical point of view, while targeting different industries that implemented specific AI solutions for optimizations of different processes. In the second one, we ca retrieve researchers that are rather focused on the need of an AI ethics in all domains, working on finding solutions/framework that could answer to issues and concerns generated by AI. Hence, one future research direction could be to map the need of an AI ethics framework in business with respect to the impact that AI can generate for both business landscape and its consumers.

Another interest on this paper was to identify the most representative institutions that are contributing to the research of AI ethics in business topics. One key finding here was that the fist 2 most prolific institutions researching AI ethics in business have dedicated digital labs (see Oxford Digital Ethics Lab, or Digital Society Institute at University of Twente). Also, 13 out of 15 most exponential institutions in this analysis are also part of the top 200 World Universities ranking for year 2021 (QS World University Rankings, 2021) and the criteria for these evaluations were mainly related to the quality of research and the number of citations. Obviously, that could be a good indicator showing that the research of AI ethics in business needs investments and budgets that could afford an end-to-end research strategy that brings together academia, the public sector, nongovernmental organization as well as public administrations.

On the other side this paper identified that the key pattern in terms of collaboration, is the domestic one or maximum a regional one (looking at the EU or the Asian countries).The English-speaking countries have more research published on the AI ethics in business but without having cross-country collaborations. Other countries such as China and other Asian ones (Taiwan, India, Vietnam, South Korea, Malaysia) are well ranked as important contributors but among their advantages, the most important is that there is a strong collaboration between these in terms of coauthorship. Comparably, the European countries such as Germany, the Netherlands, Italy, Spain, and France produce a large volume of research together as a single entity.

Finally, this paper reported on the main topics and current emerging issues surrounding the AI ethics in business, and here we can clearly see a focus around four big clusters that were retrieved after analyzing the keywords obtained with cooccurrence analysis in VOSviewer. These clusters are mainly referring linked to Data Security and Privacy (associated with AI systems), robotics and automations (robots, autonomous cards, drones etc.), humans (i.e., the impact of AI on humans and the potential issue of workers losing jobs due to AI automation solutions) and ethics (with respect to AI impact on society, on business decision-making, healthcare etc.). Based on these findings, we cand see that topic such as technology 
and subsequently artificial intelligence, big data, and autonomous systems (i.e., robots, self-driving cars) are questioned from the perspective of their impact on humans, economy, and society.

\subsection{Limitations and further research opportunities}

We are expecting that further bibliometric research opportunities will overcome our current limitations. One of the main limitations was related to Scopus database itself because by default it is not allowed to export the full bibliographical information of more than 2000 articles. In this context, we had to filter the first 2000 most cited and that was our main work dataset. Additionally, another limitation was related to the data visualization tools. VOSviewer is a great data visualization tool, but it does not allow to perform a mapping of different results (i.e., creating matrix diagrams that maps authors, journals, and institutions). Since a bibliometric analysis is quantitative research than it will be beneficial to have even more documents and data sources. For instance, one of the next research directions could be to extend the search strategy in Scopus or other well-ranked database and to capture all related articles.

On the other side, a new research direction could be to use an extended search strategy that will focus only on business journals. This way we can capture the interest of business and management review in AI and how these technologies are perceived. Another further research direction can be related to how AI systems are used in the strategic decision-making processes and how performant these are based on specific business criteria. Based on these research directions, we can identify patterns regarding the need of AI ethics in business while capturing the associated impact on society, economy, education. In the end, the AI ethics in business research should not be about good or bad, but rather about efficiency, transparency and fairness and about having a framework to guide towards a successful AI systems implementation.

Acknowledgements: This paper is partially supported by the Competitiveness Operational Programme Romania under project number SMIS 124759 - RaaS-IS (Research as a Service Iasi), POC/398/1/1, SMIS 124759, ctr. nr. 236/21.04.2020 


\section{REFERENCES}

1. Abadi, S. et al., 2018. Application model of k-means clustering: Insights into promotion strategy of vocational high school. International Journal of Engineering and Technology(UAE), 7(2.27), pp. 182-187.

2. Aloini, D., Latronico, L. \& Pellegrini, L., 2021. The impact of digital technologies on business models. Insights from the space industry. Measuring Business Excellence, Volume ahead-of-print.

3. Amit, R. \& Zott, C., 2012. Creating value trough Business Model Inovation. MIT Sloan Management Review, Volume 53, pp. 41-49.

4. Baek, C. \& Doleck, T., 2020. A Bibliometric Analysis of the Papers Published in the Journal of Artificial Intelligence in Education from 2015-2019. International Journal of Learning Analytics and Artificial Intelligence for Education, 2(1).

5. Bagdasarov, Z. et al., 2013. Case-Based Ethics Instruction: The Influence of Contextual and Individual Factors in Case Content on Ethical Decision-Making. Science and Engineering Ethics, 19(3), pp. 1305 - 1322.

6. Beauchamp, T. L. \& Childress, J. F., 2009. Principles of biomedical ethics. 6th Edition ed. New York: Oxford University Press.

7. Bolukbasi, T. et al., 2016. Man is to computer programmer as woman is to homemaker? debiasing word embeddings in Proceedings of the 30th International Conference on Neural Information Processing Systems. Barcelona, Curran Associates Inc., p. 4356-4364.

8. Bosk, C., 2010. Bioethics, Raw and Cooked: Extraordinary Conflict and Everyday Practice. Journal of Health and Social Behavior, Volume 51, pp. 133-146.

9. Bossmann, J., 2016. Top 9 ethical issues in artificial intelligence. [Online]Available at: https://www.weforum.org/agenda/2016/10/top-10-ethical-issues-in-artificialintelligence/ [Accessed 0608 2021].

10. Brundage, M. et al., 2018. The Malicious Use of Artificial Intelligence: Forecasting, Prevention, and Mitigation. [Online]

Available at: https://doi.org/10.17863/CAM.22520

[Accessed 1507 2021].

11. Bynum, T. W., 2001. Computer ethics: Its birth and its future. Ethics and Information Technology volume, Volume 3, pp. 109-112.

12. Byrne, E. F., 1972. The drama of realtime complementarity. The Philosophy Forum, 11(1-2), pp. 167-206.

13. Capurro, R., 2010. DIGITAL ETHICS. Seoul, The Academy of Korean Studies.

14. Cath, C., Sandra Wachter, B. M., Taddeo, M. \& Floridi, L., 2018. Artificial Intelligence and the 'Good Society': the US, EU, and UK approach. Science and Engineering Ethics, Volume 24, pp. 505-526.

15. Commission, E., 2019. Ethics guidelines for trustworthy AI. [Online] Available at: https://digital-strategy.ec.europa.eu/en/library/ethics-guidelinestrustworthy-ai [Accessed 0609 2021].

16. Copeland, B., 2020. Encyclopedia Britannica. [Online] Available at: https://www.britannica.com/technology/artificial-intelligence [Accessed 0406 2021]. 
17. Crawford, K. \& Ryan, C., 2016. There is a blind spot in AI research. Nature, Volume 538, pp. 311-313.

18. Davenport, T., Guha, A., Grewal, D. \& Bressgott, T., 2020. How artificial intelligence will change the future of marketing. Journal of the Academy of Marketing Science, Volume 48, pp. 24-42.

19. Davenport, T. H. \& Ronanki, R., 2018. Artificial Intelligence for the Real World. Harvard Business Review, 96(1), pp. 108-116.

20. Delipetrev, B., Tsinaraki, C. \& Kostic, U., 2020. Historical Evolution of Artificial Intelligence, Luxembourg: EUR $30221 \mathrm{EN}$, Publications Office of the European Union.

21. Dignum, V., 2018. Ethics in artificial intelligence: introduction to the special issue. Ethics and Information Technology, Volume 20, pp. 1-3.

22. Donthu, N. et al., 2021. How to conduct a bibliometric analysis: An overview and guidelines. Journal of Business Research, Volume 133, pp. 285-296.

23. Dwivedi, Y. et al., 2021. Artificial Intelligence (AI): Multidisciplinary perspectives on emerging challenges, opportunities, and agenda for research, practice and policy,. International Journal of Information Management, Volume 57.

24. Editorial from Nature magazine, 2017. Science must examine the future of work.. Nature, Volume 550, pp. 301-302.

25. Eurobarometer, E. C., 2015. Autonomous Systems. [Online] Available at: https://europa.eu/eurobarometer/surveys/detail/2018 [Accessed 1206 2021].

26. Filipović, A., Koska, C. \& Paganini, C., 2018. Alexander Filipović, Christopher Koska, Claudia Paganini. [Online]

Available at: https://www.bertelsmannstiftung.de/en/publications/publication/did/developing-a-professional-ethics-foralgorithmists/ [Accessed 1008 2021].

27. Floridi, L. et al., 2018. An Ethical Framework for a Good AI Society: Opportunities, Risks, Principles, and Recommendations. Minds and Machines, Volume 28, pp. 689707.

28. Floridi, L. et al., 2018. AI4People-An Ethical Framework for a Good AI Society: Opportunities, Risks, Principles, and Recommendations. Minds and Machines, Volume 28, pp. 689-707.

29. Greene, D., Hoffman, A. L. \& Stark, L., 2019. Better, Nicer, Clearer, Fairer: A Critical Assessment of the Movement for Ethical Artificial Intelligence and Machine

Learning. [Online]

Available at: http://hdl.handle.net/10125/59651

[Accessed 0408 2021].

30. Guo, Y. et al., 2020. Artificial Intelligence in Health Care: Bibliometric Analysis. $J$ Med Internet Res , 22(7).

31. Hagerty, A. \& Rubinov, I., 2019. Global AI Ethics: A Review of the Social Impacts and Ethical Implications of Artificial Intelligence. [Online]

Available at: https://arxiv.org/ftp/arxiv/papers/1907/1907.07892.pdf [Accessed 2408 2021].

32. Hamid, A. et al., 2018. Determining basic food quality using SAW. International Journal of Engineering and Technology(UAE), 7(4), pp. 3548-3555. 
33. Harari, Y. N., 2017. Reboot for the AI revolution. Nature, Volume 550, pp. 324-327.

34. Huang, M.-H., Rust, R. \& Maksimovic, V., 2019. The Feeling Economy: Managing in the Next Generation of Artificial Intelligence (AI). California Management Review, 4(43-65), p. 61.

35. Irawan, D., Huda, M., Teh, K. \& Maseleno, A., 2019. Decision support system for determining pharmacy service quality. Journal of Computational and Theoretical Nanoscience, 16(12), pp. 4970 - 49778.

36. Jobin, A., Ienca, M. \& Vayena, E., 2019. The global landscape of AI ethics guidelines. Nature Machine Intelligence, Volume 1, pp. 369-299.

37. Jonas, H., 2014. Technology and Responsibility: Reflections on the New Tasks of Ethics. Sandler R.L. (eds) Ethics and Emerging Technologies ed. London: Palgrave Macmillan.

38. Jordan, M. \& Mitchell, T., 2015. Machine learning: Trends, perspectives, and prospects. Science, 349(6245), pp. 255-260.

39. Kaplan, A. \& Haenlein, M., 2020. Rulers of the world, unite! The challenges and opportunities of artificial intelligence. Business Horizons, 63(1), pp. 37-50.

40. Kumar, V., Rajan, B. \& Rajkumar Venkatesan, L. J., 2019. Understanding the Role of Artificial Intelligence in Personalized Engagement Marketing. California Management Review, 61(4), pp. 135-155.

41. Loureiro, S. M., Guerreiro, J. \& Tussyadiah, I., 2021. Artificial intelligence in business: State of the art and future research agenda,. Journal of Business Research, Volume 129, pp. 911-926.

42. Floridi, L., 2013. Distributed morality in an information society. Science and Engineering Ethics, Volume 19, pp. 727-743.

43. Floridi, L., 2016. Faultless responsibility: on the nature and allocation of moral responsibility for distributed moral actions. Phil. Trans. R. Soc. A, 374(2083).

44. Marturano, A., 2002. The role of metaethics and the future of computer ethics. Ethics and Information Technology, Volume 4, pp. 71-78.

45. McKinsey, 2021. https://www.mckinsey.com/featured-insights/future-of-work/thefuture-of-work-after-covid-19. [Online]

Available at: https://www.mckinsey.com/featured-insights/future-of-work/the-futureof-work-after-covid-19

[Accessed 0608 2021].

46. Miller, S., 2018. AI: Augmentation, more so than automation. Asian Management Insights, 5(1), pp. 1-20.

47. Mittelstadt, B., 2019a. Principles alone cannot guarantee ethical AI. Nature Machine Intelligence, Volume 1, pp. 501-507.

48. Müller, V. C., 2020. Ethics of artificial intelligence and robotics. In: E. N. Zalta, ed. Stanford Encyclopedia of Philosophy. Palo Alto: CSLI, Stanford University, pp. 1-70.

49. Narayanan, S., 2021. Why AI ethics Requires a Culture-Driven Approach. [Online]

Available at: https://www.linkedin.com/pulse/why-ai-ethics-requires-culture-drivenapproach-narayanan/

[Accessed 2408 2021].

50. Nijsingh, N. \& Düwell, M., 2009. Interdisciplinarity, Applied Ethics and Social Science. Evaluating New Technologies, Volume 3, pp. 79-92.

51. Norbert, W., 1954. The Human Use of Human Beings: Cybernetics and Society. Doubleday Anchor ed. s.1.:Houghton Mifflin. 
52. Norbert, W., 1959. Man and the Machine. Challenge, Taylor \&Francis Journals, 7(9), pp. 36-41.

53. Parliament, E., 2019. European Parliament resolution of 12 February 2019 on a comprehensive European industrial policy on artificial intelligence and robotics. [Online]

Available at: https://www.europarl.europa.eu/doceo/document/TA-8-20190081_EN.html\#: :text=European\%20Parliament\%20resolution\%20of\%2012\%20Febr uary\%202019\%20on,policy\%20on\%20artificial\%20intelligence\%20and\%20robotics \%20\%282018\%2F2088\%20\%28INI\%29\%29[Accessed 0908 2021].

54. PwC, 2017. PwC's Global Artificial Intelligence Study: Exploiting the AI Revolution. [Online]

Available at: https://www.pwc.com/gx/en/issues/data-andanalytics/publications/artificial-intelligence-study.html [Accessed 0608 2021].

55. PwC, 2021. https://www.pwc.com/gx/en/ceo-agenda/ceosurvey/2021/report.html. [Online]

Available at: https://www.pwc.com/gx/en/ceo-agenda/ceosurvey/2021/report.html [Accessed 0608 2021].

56. Robinette, P., Wagner, A. R. \& Howard, A. M., 2013. Building and Maintaining Trust Between Humans and Guidance Robots in Emergency. In Trust and Autonomous

Systems: 2013 AAAI Spring Symposium. [Online]

Available at:

https://www.aaai.org/ocs/index.php/SSS/SSS13/paper/download/5755/6007

[Accessed 1207 2021].

57. Sayre-McCord, G., 2014. Stanford Encyclopedia of Philosophy, Methaethics. [Online] Available at: https://plato.stanford.edu/entries/metaethics/

[Accessed 0808 2021].

58. Shankar, V., 2018. How Artificial Intelligence (AI) is Reshaping Retailing. Journal of Retailing, 94(4), pp. 6-11.

59. Singer, P., 2021. Encyclopedia Britannica. [Online]

Available at: https://www.britannica.com/topic/ethics-philosophy

[Accessed 0608 2021].

60. Singh, V. \& Gochhait, S., 2020. THE DEVELOPMENT OF ARTIFICIAL INTELLIGENCE IN HEALTH AND MEDICINE: A BIBLIOMETRIC ANALYSIS. European Journal of Molecular \& Clinical Medicine, 7(6), pp. 2585-2594.

61. Song, P. \& Wang, Z., 2020. A bibliometric analysis of worldwide educational artificial intelligence research development in recent twenty years. Asia Pacific Education Review, Volume 21, p. 473-486.

62. Stahl, B. C., Timmermans, J. \& Mittelstadt, B. D., 2016. The Ethics of Computing: A Survey of the Computing-Oriented Literature. ACM Computing Surveys, 48(4), pp. 138.

63. Stone, P. et al., 2016. "Artificial Intelligence and Life in 2030." One Hundred Year Study on Artificial Intelligence: Report of the 2015-2016 Study Panel, Stanford, CA: Stanford University.

64. Su, H. \& Lee, P., 2010. Mapping knowledge structure by keyword co-occurrence: a first look at journal papers in Technology Foresight. Scientometrics, Volume 85, pp. 65-79. 
65. Tambe, P., Peter, C. \& Yakubovic, V., 2019. Artificial Intelligence in Human Resources Management: Challenges and a Path Forward. California Management Review, 61(4), pp. 15-42.

66. TopUniversities, 2021. Universities Rankings. [Online]

Available at: https://www.topuniversities.com/university-rankings/world-universityrankings/2021

[Accessed 07 August 2021].

67. Veale, M. \& Binns, R., 2017. Fairer machine learning in the real world: Mitigating discrimination without collecting sensitive data. Big Data \& Society.

68. Whittlestone, J., Nyrup, R. \& Alexandrova, A., 2019. Ethical and societal implications of algorithms, data, and artificial intelligence: a roadmap for research.

London: Nuffield Foundation. [Online]

Available at: https://www.nuffieldfoundation.org/sites/default/files/files/Ethical-and-

Societal-Implications-of-Data-and-AI-report-Nuffield-Foundat.pdf

[Accessed 1008 2021].

69. Wilson, J. \& Daughery, P., 2018. Collaborative Intelligence: Humans and AI Are Joining Forces. Harvard Business Review, 96(4), pp. 114-123.

70. Winfield, A. F. T. \& Jirotka, M., 2018. Ethical governance is essential to building trust in robotics and artificial intelligence systems. Phil. Trans. R. Soc. A, 376(2133).

71. Yufei, L. \& Zhongbao, L., 2019. The development of artificial intelligence: a bibliometric analysis, 2007-2016. Journal of Physics: Conference Series, 1168(2).

72. Yuh-Shan, H. \& Wang, M.-H., 2020. A bibliometric analysis of artificial intelligence publications from 1991 to 2018. Journal of Scientometrics and Information Management, 14(2), pp. 369-392.

73. Zhang, Y. et al., 2021. Ethics and privacy of artificial intelligence: Understandings from bibliometrics. Knowledge-based Systems, 222(106994).

74. Zott, C. \& Amit, R., 2010. Business Model Design: An Activity System Perspective. Long Range Planning, 43(2), pp. 216-226.

75. Zou, J. \& Schiebinger, L., 2018. AI can be sexist and racist - it's time to make it fair. Nature, Volume 559, pp. 324-326. 